\title{
Formación Del Docente De Educación Especial Y La Educación Inclusiva Como Política
}

Del Estado Venezolano

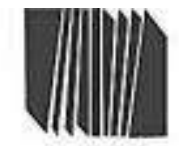

Unavcesigan ofroneocece

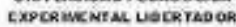

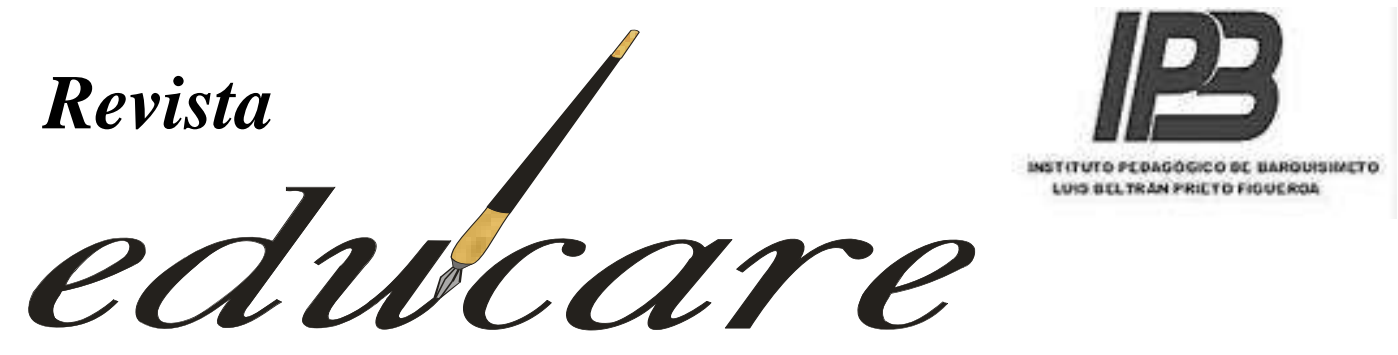

Órgano Divulgativo de la Subdirección de Investigación y Postgrado del Instituto Pedagógico de Barquisimeto "Luis Beltrán Prieto Figueroa"

Barquisimeto estado Lara EDICIÓN XX ANIVERSARIO

\section{Volumen 21 № 1 Enero - Abril 2017}

FORMACIÓN DEL DOCENTE DE EDUCACIÓN ESPECIAL Y LA EDUCACIÓN INCLUSIVA COMO POLÍTICA DEL ESTADO VENEZOLANO

Training of special education teachers and inclusive education

As policy of the venezuelan state

I S S N : $2244-7296$

Autor

Debbiee Carmona de Sada

María Rodríguez Polanco

UPEL-IPB 
Investigación

Recibido: 10-11-2016

\section{RESUMEN}

La educación inclusiva necesita que la Modalidad de Educación Especial cuente con un docente capaz de diversificar su rol orientador con miras a promover la participación efectiva de todos los actores sociales del hecho educativo, en $\mathrm{y}$ para el fomento de valores inclusivos que favorezcan la atención educativa del estudiantado, sin discriminación. El objetivo de esta investigación documental fue analizar la formación del docente de Educación Especial en consonancia con los desafíos de la Educación Inclusiva como Política del Estado venezolano. Se analizaron fuentes bibliográficas y electrónicas sobre educación inclusiva y su fundamentación legal internacional y nacional. Esto posibilitó la reflexión para la construcción de un marco conceptual que permita vislumbrar la formación del docente de Educación Especial. Se concluyó en la necesidad de que este docente gestione un trabajo mancomunado familia-escuela-comunidad como parte sustantiva del proceso educativo inclusivo y promueva los cambios concienciales requeridos en la comunidad escolar.

Descriptores: formación docente, educación especial, educación inclusiva.
Debbie Carmona de Sada* María Rodríguez Polanco ** UPEL IPB

Aceptado:17-02-2017

\section{ABSTRACT}

Inclusive education requires that the Special Education Mode has a teacher capable of diversifying its guiding role with a view to promoting the effective participation of all social actors of the educational event, in and for the promotion of inclusive values that favor the educational attention of the student, without discrimination. The objective of this documentary research was to analyze the education of the Special Education teacher in line with the challenges of Inclusive Education as a Venezuelan State Policy. We analyzed bibliographic and electronic sources on inclusive education and its international and national legal basis. This made possible the reflection for the construction of a conceptual framework that allows glimpsing the formation of the teacher of Special Education. It wasconcludedthat it isnecessary for thisteachertomanage a joint family-schoolcommunitywork as a substantive partofthe inclusive

educationalprocessandtopromotethepertinentchang esrequired in theschoolcommunity.

Keywords: teaching training, specialeducation inclusive education

*Debbiee Carmona de Sada, Licenciada en Educación, mención Dificultades del Aprendizaje (UNA), Especialista en Educación Especial (UPEL-IPB),Docente Agregado de pregrado y postgrado (UPEL-IPB). debbieecarmona@gmail.com

** María Rodríguez Polanco,Licenciada en Educación, mención Dificultades del Aprendizaje (UNA), Magister en Lingüística (UPEL-IPB), Docente Agregado de pregrado y postgrado (UPEL-IPB), mariarosalia2007@hotmail.com 
Formación Del Docente De Educación Especial Y La Educación Inclusiva Como Política

Del Estado Venezolano

Debbiee Carmona de Sada, María Rodríguez Polanco

(Pp.27-49)

\section{INTRODUCCIÓN}

"Si no lo creo no lo veo" (Von Foerster)

El docente venezolano afronta una nueva realidad educativa que le avasalla y exige cambios en su praxis, pues el escenario que presenta las políticas de Estado se orienta hacia la inclusión educativa. Entender la complejidad que tiene esta tendencia es un gran reto, particularmente desde la Educación Especial, ya que supone romper paradigmas y repensar el nuevo rol que debe cumplir el docente de esta Modalidad para hacer frente a la nueva demanda socioeducativa. En este sentido, nuestra ocupación como docentes universitarios es advertir los radicales cambios que se están produciendo en los ámbitos social, educativo, cultural y político, tanto a nivel mundial, nacional y local en materia de atención educativa a la diversidad humana, para así dar respuesta a estos requerimientos.

Este movimiento de atención educativa, obliga a quienes estamos directamente involucrados en la formación docente a analizar las nuevas perspectivas de la Educación Especial en el marco de la educación inclusiva, y reflexionar sobre el rol requerido y el nuevo accionar del docente de Educación Especial, especialmente ese educador que se ha formado en el área de Dificultades de Aprendizaje en nuestra casa de estudio, la Universidad Pedagógica Experimental Libertador (UPEL).

De allí, que en el marco de la Educación Inclusiva se aluda a la necesidad de actualizar la formación de todos los docentes. En esta tarea de formación se resalta al docente de la Modalidad de Educación Especial, con un rol orientador bien puntual en la consecución de esta nueva educación, la cual amplía las posibilidades educativas a toda la población en contextos compartidos y sin discriminación alguna. Dicho docente debe contagiar la visión de la atención inclusiva a todos los actores del hecho educativo para fomentar valores inclusivos como: el respeto a la diversidad (característica humana compartida), respeto a la ciudadanía, la tolerancia, el amor, la solidaridad y la cooperación.

En este orden de ideas, el florecer del nuevo modelo de Educación Inclusiva en Venezuela, reclama el derecho de todas las personas a recibir su educación en contextos menos restrictivos. De manera que se amplía y diversifica las funciones que hasta ahora venían cumpliendo los docentes de Educación Especial. Ahora, no solo se trata de atender 
a la población con Necesidades Educativas Especiales (NEE) en sus unidades operativas, ni de acompañar al docente de aula común en el proceso de atención educativa de los educandos especiales. Además de esto, deben orientar a todos los actores del hecho educativo en la labor que a cada uno le corresponda en el proceso inclusivo, y generar espacios de encuentro para la participación, el debate, la propuesta y la reflexión. De tal manera, que los docentes de Educación Especial, en los diferentes niveles y Modalidades del Sistema Educativo Venezolano, deben ser promotores de cambios concienciales en las comunidades escolares.

De lo anterior, se deriva la necesidad de que las universidades formadoras de docentes en el área de la Educación Especial, perfilen su accionar hacia la reflexión permanente, con miras a la renovación. Así, estas instituciones deben lograr el egreso de profesionales reflexivos; capaces de insertarse con pertinencia y sensibilidad en los contextos educativos actuales en los cuales les corresponde ser orientadores por excelencia a los docentes de las instituciones educativas comunes, las familias y comunidad en general. En consecuencia, se trata de una alta responsabilidad social la que ahora se les atribuye a los formadores; es decir, a los docentes universitarios en el área de la pedagogía, quienes ahora ven conmovida su labor en los ámbitos de la docencia, extensión e investigación para la consecución del reto que les plantea la Educación Inclusiva.

\section{LA MIRADA PRINCIPAL}

Analizar la formación del docente de Educación Especial en consonancia con los desafíos de la Educación Inclusiva, Política del Estado venezolano.

\section{Apología de la Nueva Mirada}

El Estado venezolano en el 2011 introdujo la Política Pública de la Modalidad de Educación Especial (MEE) con carácter inclusivo, cuyo propósito fue solventar problemáticas de exclusión y discriminación de las personas con NEE dentro del sistema educativo común. Sin embargo, este proceso trajo consigo resistencia en los docentes, tanto en las unidades operativas de la MEE como en la escuela común, donde aún se tiene una 
visión homogénea de la atención a las personas con discapacidad, Estos últimos docentes han manifestado el miedo natural y la inseguridad que produce enfrentar situaciones desconocidas e impuestas; ya que el Estado venezolano implementó los cambios sin consultar a instituciones asesoras por excelencia, como las universidades; o a la familia y el profesorado del subsistema de Educación Básica y la MEE.

De allí, la importancia de construir y promover un marco conceptual pertinente que sustente la revisión de formación del docente de Educación Especial que acompañe u oriente a aquellos educadores de la educación común, para favorecer la atención de las personas con NEE en los diversos espacios educativos. La presencia orientadora del profesional de la docencia de Educación Especial, puede representar una alternativa que permita enriquecer ambientes de aprendizaje para todos los actores sociales del hecho educativo, y fomentar la construcción de valores humanos indispensables para el establecimiento de relaciones sociales armónicas.

Po lo tanto, el estudio representó un tema de vital interés, ya que aporta reflexiones y alternativas de carácter pedagógico indispensables para su consideración en la formación del docente de Educación Especial. En la actualidad es imperante que este profesional sea capaz de acompañar y fortalecer el proceso de inclusión educativa que se emprendió en el país.

No cabe duda que existe la necesidad de operativizar adecuadamente la atención educativa de la población con NEE que están ingresando a las instituciones educativas comunes. Por consiguiente, el docente de la MEE es un eslabón importante en la cadena de actores sociales que juega un papel activo para coronar una verdadera inclusión educativa; máxime, si como se ha mencionado, existe resistencia ante esta nueva realidad educativa.

\section{METODOLOGÍA}

Para la construcción de este trabajo se procedió a realizar una revisión documental, definida en el Manual de Trabajos de Grado de Especialización y Maestría y Tesis Doctorales de la UPEL (2006) como "el estudio de problemas con el propósito de ampliar o profundizar el conocimiento de su naturaleza, con apoyo, principalmente, en trabajos 
previos, información y datos divulgados por medios impresos, audiovisuales o electrónicos" (p.20).

Asimismo, la tipología documental monográfica es definida por Alfonso 1995, citado por Morales 2003, como un procedimiento científico; un proceso sistemático de indagación, recolección, organización, análisis e interpretación de información o datos en torno a un determinado tema. Al igual que otros tipos de investigación, éste conduce a la construcción de conocimientos o a realizar algún aporte sustancial a la problemática planteada.

En efecto, se pretendió profundizar en la problemática socioeducativa por la que atraviesan hoy los docentes de los diferentes niveles del sistema educativo venezolano, en relación a la inclusión educativa de las personas con discapacidades. Por cuanto, a raíz del dictamen del Estado venezolano de su incorporación en las instituciones de todos los niveles educativos, se ha convertido en una compleja realidad que necesita ser abordada desde los ámbitos pedagógico, sociológico y psicológico.

En este sentido, el trabajo ameritó la revisión de fuentes formales impresas y electrónicas. Es decir, se usaron técnicas para recabar la información, que según Finol, T. y Nava, H. (1996) comprenden actividades que permiten al investigador obtener información para dar respuesta al objetivo de la investigación. Para ello se procedió a:

La búsqueda: Guiada por la necesidad de encontrar un conocimiento nuevo o más profundo de lo ya establecido. Esta actividad incluyó la visita a centros de documentación científicos y tecnológicos: bibliotecas, hemeroteca, portales electrónicos oficiales de organismos gubernamentales (Ministerio de Poder Popular Para la Educación (MPPPE), MEE) y otros.

Lectura: Se procedió a la lectura exploratoria de documentos con la finalidad de indagar su pertinencia con la temática, y seleccionar aquellos que pudieran ser referencias para contribuir al el objetivo establecido en la investigación. Luego de seleccionar cada documento se realizó una lectura más cuidadosa para realizar una evaluación del contenido del material y su aporte científico y social a la temática en estudio. Seguidamente, se consideró en el análisis de los materiales o documentos, elementos como: identificación del autor, méritos que poseía, título del material, casa editorial, el año y lugar de la publicación, 
si se trataba de una fuente primaria; entre otros aspectos propios para los documentos electrónicos y audiovisuales.

Recolección de información: Fue una etapa laboriosa que ocupó un tiempo considerado, pues implicó realizar una compilación documental de información que las autoras consideraron útiles para su análisis, interpretación y deducción de aportes al estudio. Esta etapa fue crucial y de gran valor académico, ya que nos permitió como investigadoras realizar un trabajo de reflexión profunda, al entrar en contacto con una vasta información que pudimos contrastar con nuestra realidad educativa actual y el capital cultural que hemos cosechado a lo largo de nuestra experiencia profesional, tanto en el subsistema de Educación Básica como el subsistema de Educación Universitaria. Con lo cual permitió aportar al conocimiento de la temática inclusiva que ha cobrado relevancia en Venezuela en los últimos años.

Selección y registro de datos: La selección entre toda la documentación recogida se hizo de manera intencionada, guiada naturalmente por los objetivos establecidos en la investigación. El registro se realizó a través de dos formas: En la primera, se empleó la técnica denominada Folder, por medio de la cual, se recoge la información en hojas sueltas que luego se van agregando a una carpeta organizada en función del esquema de trabajo preestablecido por los objetivos de la investigación. La segunda forma de hacer los registros, se efectuó directamente con el uso del ordenador electrónico, resaltando las ideas principales de los documentos electrónicos consultados.

Análisis, interpretación y aporte personal: Una vez realizadas las actividades anteriores, éstas permitieron la estructuración de un contenido que se ubicó en la sección de referentes teóricos, producto de un proceso crítico y reflexivo por parte de las autoras que sirvió de base para su aporte personal, describiendo las implicaciones que tiene para las instituciones educativas comunes la implementación de la Política Pública de la MEE; determinando cuáles serían las acciones que debe llevar adelante el docente de Educación Especial en su rol orientador y del proceso de inclusión educativa de los educandos con NEE.

Toda investigación debe suponer la existencia de un rigor científico. Para el caso de la investigación documental, éste viene determinado por la autenticidad y confiabilidad de los documentos usados en la consulta. Para Balestrini (2002) la cuestión de la confiabilidad de 
la documentación usada es un problema que debe resolver el investigador en la medida de lo posible y asegurarse de que la información que posee es auténtica. Asegura: "Lo auténtico está ligado a lo verdadero... depende de la posibilidad que tuvo el autor de conocer bien los hechos y de la sinceridad del relato que de ellos hace." (p. 63) Viéndolo desde este punto de vista, se apela al aspecto ético del investigador. En consecuencia, debimos ser acuciosas en la búsqueda, selección y tratamiento de la documentación escogida. Deslastrarnos de nuestras percepciones particulares, para que a partir de la dialógica entre investigadoras y los documentos escudriñados, arribáramos a conclusiones y reflexiones lo más genuinas u honestas posibles, en relación a la formación del docente de la MEE en el contexto de la Educación Inclusiva como política del Estado venezolano.

\section{LUCES QUE GUIARON LA NUEVA MIRADA}

En la revisión y análisis documental de carácter internacional conseguimos que Venezuela como uno de los 188 países miembro de la Organización de las Naciones Unidas para la Educación, la Ciencia y la Cultura (UNESCO), no esté exenta de los planteamientos sobre Educación Inclusiva. Por lo tanto, ha asumido como una de sus políticas de Estado la inclusión educativa de las personas con NEE al sistema educativo regular o común; formulando cambios en la manera de concebir la atención académica para dichas personas, la cual se viene dando mayormente, aislada del resto de los educandos sin discapacidad. Así se les ha negado a los educandos con NEE la posibilidad de ampliar el potencial humano a través de la mediación de sus pares más competentes, tal como lo plantea la teoría vygotskiana.

Esta realidad socioeducativa ha sido vislumbrada en el mundo, tal como lo señaló la UNESCO (2007), en su informe de seguimiento de la Educación Para Todos, en el que se planteó la interrogante: ¿Se alcanzará para el 2015 la meta de atención a los grupos sociales minoritarios que históricamente han sido marginados del sistema educativo oficial?, entre los cuales destaca el de las personas con alguna discapacidad o NEE. Dicha respuesta está a la espera de los informes de avance de cada nación, no sólo en la ejecución de políticas que garanticen tal fin, sino también de su evaluación.

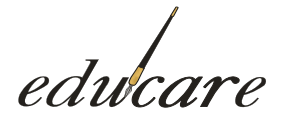

Volumen $21 N^{\circ} 1$ Enero-Abril 2017. ISSN: 2244-7296 
En el documento de la MEE en el Marco de la Educación Bolivariana "Educación sin Barreras” del MPPPE (2011), se expone que a escala internacional los sistemas educativos creen en la Educación Inclusiva como perspectiva orientada a la atención de las personas que presentan NEE y al desarrollo de programas que apoyen la inclusión educativa de niños y adolescentes, que por sus características y necesidades diferentes están siendo excluidos de la Educación Primaria y otros ámbitos. En este documento se concluye que, la transformación de la MEE hacia todo el sistema educativo es la vía para alcanzar la plena inclusión de los estudiantes con discapacidad.

Asimismo, el MPPPE (2011) reportó que del censo realizado por la Misión José Gregorio Hernández, existía un total de 89.131 niños, niñas, adolescentes, jóvenes y adultos con discapacidad sin escolarización. De ese total, 14.756 eran menores de 18 años. Además, agregó que en la MEE se mantiene un modelo de atención clínico y asistencialista, a pesar de que en su Conceptualización y Política revisada en el año 2007 se estipula el modelo de atención educativa integral, con una visión humanista y socio histórico - cultural. También señaló la existencia de barreras de accesibilidad en la infraestructura de las escuelas, y barreras actitudinales, tanto en las escuelas comunes como en las comunidades.

Con estos argumentos el Estado venezolano, a través del MPPPE, decidió en el 2011 poner en marcha la nueva Política Pública en la MEE, en la cual se establecía su transformación, con repercusiones en todos los niveles del sistema educativo del país, generándose unas implicaciones en la atención educativa que obligaba al docente de Educación Especial a renovar tanto su visión como su misión en la escuela común. En consecuencia, remitía a repensar su formación.

Todos estos planteamientos del MPPPE se desprenden de los acuerdos internacionales subscritos por Venezuela, en los cuales la educación mundial vista desde la homogeneidad atraviesa una crisis que exige a los Estados, por un lado, una decidida voluntad política para acometer los cambios y medidas necesarias que den un giro a este tipo de educación; y por otro lado, demanda a las universidades formadoras de maestros, verdaderas transformaciones en la formación del profesional de la docencia. Se necesita un docente capaz de brindar educación de calidad a todos sus habitantes, más aún, si lo que se está 
proponiendo es una escuela para todos. Tal como lo establece la amplia normativa legal que en los ámbitos internacional, nacional y local fundamenta la educación inclusiva.

Sin embargo, todos los planteamientos de la Educación Inclusiva que apuntan a una sola escuela para todos, creemos que deben ser revisados con detenimiento. Si bien es cierto que podemos encontrar personas con discapacidades altamente resilientes, capaces de desarrollar su máximo potencial humano; también es cierto que existen otras con condiciones altamente complejas (debido a etiologías orgánicas a nivel del sistema nervioso central) que ameritan espacios educativos altamente estructurados y con la participación permanente de profesionales de diversas disciplinas. Tales son las situaciones que presentan las personas con Trastorno del Espectro Autista (grado III), personas con discapacidad intelectual de mayor compromiso en su integridad cognitiva, o las personas con discapacidad mental.

En consonancia con lo anterior, la sociedad reclama a las universidades la formación de un docente de la MEE Educación Especial con una conciencia y práctica renovadas. Para ello, en palabras de Ugas (2010) es necesario asumir, la triada conceptual conocer, pensar y reflexionar para entender la diferencia. Es decir, la comprensión y conjunción de los conceptos otredad, mismidad y alteridad. El autor referido, define esta triada conceptual como:

El hombre es tal en tanto existe un semejante, lo cual remite a la teoría y realidad del Otro: yo soy porque hay otro que me permite serlo (otredad), pero en la relación con el Otro soy lo que soy (mismidad), y entrando en conjunción con el Otro se produce una relación dialógica (alteridad). (p.19)

Por ende, esta redimensión del pensamiento se convierte en un imperativo para los docentes de las universidades encargada de la formación de educadores. De manera que, esta nueva visión del ser en el mundo pueda impactar a los futuros docentes encargados de abrir espacios para hacer posible la Educación Inclusiva que le demanda la sociedad.

Desde una perspectiva humanista, el educador es una persona a quien le interesa que sus estudiantes aprendan, crezcan y se desarrollen tanto en lo cognoscitivo como en lo personal y social. Por ello, en su rol está involucrarse en las necesidades de sus estudiantes; atendiendo todas las áreas de desarrollo del ser humano y las áreas académicas. Es un 
Formación Del Docente De Educación Especial Y La Educación Inclusiva Como Política Del Estado Venezolano

Debbiee Carmona de Sada, María Rodríguez Polanco

(Pp.27-49)

docente crítico, un cuestionador en permanente renovación; un modelo en valores que apoya a la diversidad de estudiantes, sea cual sea su condición.

En este contexto, se le exige al educador la capacidad de mediar en el estudiantado con o sin discapacidad, no sólo los procesos de aprendizaje y construcción del conocimiento, sino también en la resolución de sus problemas personales, grupales y sociales. Ha de ser un mediador por excelencia en sus conflictos de autonomía-dependencia.

De acuerdo con lo expresado, uno de los mayores desafíos que enfrenta la formación docente en los actuales momentos, reside en las exigencias planteadas por la educación inclusiva. Por ello, Slee (2010) hace referencia a que en las prácticas inclusivas se debe destacar la necesidad de que los futuros docentes y los formadores de éstos, tengan la posibilidad de comprender sus propias nociones de inclusión y reflexionarlas en la cotidianidad educativa. Es decir, ningún docente podrá adelantar un proceso de Educación Inclusiva sin antes realizar un proceso de diagnóstico personal y de reflexión para su transformación; y es precisamente el periodo de formación docente el propicio para tal fin.

Por lo tanto, un primer paso que sugiere el mencionado autor es: La transformación de la formación, que consistiría en abrir espacios en el currículum universitario de las especialidades pedagógicas que permitan reflexionar sobre cuál es la construcción de diversidad e inclusión que cada sujeto elabora, con anterioridad al desarrollo de técnicas y herramientas pragmáticas de trabajo (metodologías de enseñanza y evaluación). (p.293). De ahí que se hace necesario que los futuros docentes de la MEE dejen atrás la visión de la diferencia con una orientación al déficit y con la concepción de atención exclusivamente en las aulas especiales. Es necesario abrirse paso a la nueva cosmovisión de atención a la diversidad humana, entre las cuales las personas con discapacidad, representan una de sus formas.

Por su parte, Durán (s/f) plantea la necesidad de promover un cambio de mirada a las dificultades que el docente refiere para atender la diversidad de necesidades. Su preocupación ha de ser la búsqueda y promoción del éxito académico, personal y social de cada uno de sus estudiantes. La importancia del pensamiento del profesor, junto a las culturas organizativas; unidas al apoyo orientador del docente de Educación Especial, serán buenos garantes del éxito de la inclusión educativa.

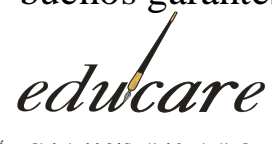

Volumen $21 N^{\circ} 1$ Enero-Abril 2017. ISSN: 2244-7296 
Definitivamente, los docentes de las instituciones educativas comunes necesitan del acompañamiento de un docente de Educación Especial que oriente y facilite una lectura más sosegada y positiva de la situación del aula. Lo que se constituye en el verdadero trabajo cooperativo hacia la calidad educativa. En este sentido, el trabajo colaborativo (mediado por el docente de Educación Especial) entre profesores, familiares, educandos y comunidad en general, es en sí mismo una estrategia para la educación inclusiva. Este es un punto importante a considerar en la formación docente.

Partiendo de la teoría histórico-cultural de Vygotski, en la que se establece que la génesis del conocimiento está en la interacción social, el docente debe estar consciente de que estos educandos demandan una atención que se fundamente en un currículo diversificado y contextualizado. Es decir, un currículo que permita la personalización de la atención de acuerdo a las capacidades, potencialidades, intereses y NEE de los educandos, siempre en interacción social con sus coetáneos. Se trata además de una personalización educativa que debe darse en un contexto donde haya la concurrencia de todos los actores del hecho educativo; en un clima de respeto, aceptación a las diferencias humanas, cooperación, solidaridad y amor. Estos valores humanos deberán ser cultivados, promovidos, reflexionados y altamente estimados; de tal manera, que pasen de la letra a la conciencia y de ésta a la acción.

No obstante, es necesario mencionar lo revelado por Rodríguez (2007), quien reportó que en un estudio realizado por la UNESCO con profesores latinoamericanos de la escuela común, éstos manifestaron no tener conocimientos en relación a la educación inclusiva; reconocen lo novedoso de la legislación y expresan poseer algunas nociones para elaborar adecuaciones curriculares; pero, los mismos no se comprometen a asumir el reto de inclusión educativa de las personas con discapacidad porque consideran que no es posible.

Creemos que aun las condiciones en las aulas comunes no están dadas para la inclusión, pues la mayoría de docentes no ha participado en programas de formación y sensibilización que generen la reflexión para que se gesten los cambios concienciales necesarios. Corresponde su promoción y desarrollo en primera instancia, a la MEE, por parte de sus docentes que se encuentren en los diferentes niveles educativos, incluyendo a los educadores de Educación Especial que están en la educación universitaria. 
Asimismo, Rodríguez (ob.cit.) concluye que los docentes del estudio presentan una ambivalencia actitudinal, pues aunque poseen conocimientos sobre la inclusión educativa de las personas con NEE, aún permanecen anclados a viejas concepciones acerca de la discapacidad, las cuales ocasionan el rechazo y la exclusión de estos estudiantes al sistema educativo común.

Valga decir, que la resistencia que se vive en las escuelas comunes, también se ha presentado en las instituciones de Educación Especial; así como también en los institutos de la UPEL, salvo el Instituto Pedagógico Barquisimeto (IPB). En este caso, durante el trabajo de transformación curricular de esta casa de estudios, reiteramos, a excepción del IPB, se pretende continuar con la formación de un profesional de la docencia acabado, afín a una NEE en particular, restando importancia a la demanda socioeducativa de un docente de la MEE, formado con un perfil amplio; capaz de impulsar el proceso de inclusión educativa.

Esta postura niega la posibilidad de considerar que hoy por hoy la escuela común se ha constituido en uno de los centros laborales por excelencia para los docentes de Educación Especial que están egresando de la UPEL y de otras instituciones universitarias. Por lo tanto, impera la necesidad de diversificar su perfil de egreso para la dar respuesta pedagógica necesaria a los educandos con diversidad de NEE que se encuentran en los ambientes de aprendizaje de todos los niveles del sistema educativo. De allí que el docente de Educación Especial deba poseer una formación pedagógica integrada al conocimiento de todas las áreas de atención de la MEE (Visual, auditiva, autismo, intelectual, físicomotora y dificultades del aprendizaje). Consideramos que en el marco de la formación permanente que construye un docente en ejercicio de su profesión, éste pueda profundizar en alguna de estas áreas (de la MEE) a través de especializaciones a nivel de postgrado.

Entre tanto, es imprescindible que el docente de Educación Especial asuma el nuevo rol que la educación inclusiva le demanda: el de orientar a los maestros de la escuela común para canalizar la acción pedagógica a los estudiantes con discapacidad que lleguen a sus manos. Además de promover el trabajo mancomunado con la familia y la comunidad. Así, se darán mejores condiciones para brindar una atención educativa de calidad y en igualdad de oportunidades a todos sus educandos. 
En este sentido, el docente de la escuela común, es por excelencia el docente inclusivo, quien debe estar dispuesto a brindar la atención educativa de calidad a todos sus educandos, inclusive a los que presentan NEE, ya que es su derecho humano y ciudadano. Lógicamente que para brindar dicha atención, este docente debe vencer el miedo natural que ocasiona enfrentar situaciones desconocidas. Es entonces, cuando entra en juego el trabajo del docente de la MEE Educación Especial, pues le corresponderá acompañarlo en la tarea de hacer posible su labor inclusiva con una nueva perspectiva. La inclusión es tarea de todos; por lo tanto, necesita contar con ambos educadores como aliados incondicionales.

Por estas razones, la autoras consideran que una manera de viabilizar la nueva misión que el Estado venezolano le ha asignado a la educación común, en su tránsito hacia una escuela inclusiva, está en que a lo largo de todo el recorrido, los maestros y demás miembros de la comunidad escolar cuenten con la orientación y compañía permanente del profesor de la MEE. Se trata de un caminar juntos en la diversidad.

Las investigadoras parten de la convicción de que educar a la diversidad humana en contextos escolares y sociales comunes, favorece la formación de seres que respeten las diferencias. Se fomenta la tolerancia, participación, solidaridad, cooperación, armonía. Así se puede formar ciudadanos que aporten al crecimiento social y cultural de la nación. La convivencia en contextos heterogéneos media la construcción de estos valores humanos tan urgidos en la sociedad venezolana de hoy.

\section{MIRADAS A LA FORMACIÓN DEL DOCENTE DE EDUCACIÓN ESPECIAL}

En la formación del docente de la MEE con mira hacia la concreción de la Educación Inclusiva, se cree necesario que este profesional egrese con competencias específicas para la atención de la discapacidad como una forma de diversidad humana. Es decir, un docente de Educación Especial preparado para atender a los educandos con cualquierNEE en contextos de inclusión. En tal sentido, se plantea que este educador en su perfil de egreso universitario posea las competencias que le permitan orientar y promover los cambios concienciales en los diferentes actores del hecho educativo. Además debe puntualizar 
Formación Del Docente De Educación Especial Y La Educación Inclusiva Como Política

Del Estado Venezolano

Debbiee Carmona de Sada, María Rodríguez Polanco

(Pp.27-49)

aspectos claves para mejorar la educación y calidad de vida de las personas con NEE. Entre éstos se destacan:

Una atención educativa integral centrada en los procesos socializantes de todos los educandos

El docente de Educación Especial, ha de considerar la socialización como una condición inherente al ser humano, fuente de conocimiento y cultura. Debe conocer la caracterización singular de los educandos en relación a su condición especial; sus capacidades, potencialidades, intereses y necesidades. Así podrá ajustar, mediante adaptaciones curriculares, su atención personalizada en los mismos ambientes de aprendizaje donde están sus compañeros sin NEE. La condición más importante que los educandos deben cumplir para ser parte de una clase, es que sean del mismo grupo etáreo.

Establecimiento de redes de apoyo con los servicios y centros educativos de la modalidad de Educación Especial

La mira debe centrarse en la formación, sensibilización y participación de los diversos actores sociales de la institución educativa común en áreas del conocimiento de la discapacidad que puedan presentar sus educandos. Para ello, el docente de Educación Especial será promotor y enlace fundamental con los servicios e instituciones de la MEE en sus diferentes áreas de atención. De esta manera, promoverá la organización de espacios académicos de formación, orientación, sensibilización y gestión de proyectos de carácter intrasectorial.

Conocimiento, comprensión e implicación de la familia especial en el proceso de inclusión educativa

El docente común necesita comprender que la atención educativa de los estudiantes con discapacidad debe hacerse con la participación activa de todos, en especial de la familia, quien representa uno de los círculos de influencia más poderosos en el desarrollo de la personalidad, valores y cultura del ser humano. Además, debe advertir la existencia de etapas psicológicas críticas por las que atraviesan las familias cuyos hijos presentan NEE.

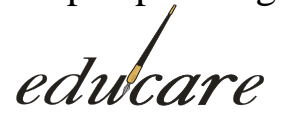

Volumen $21 N^{\circ} 1$ Enero - Abril 2017. ISSN: 2244-7296

P 41 
El docente que tiene estudiantes con NEE debe entender que este conocimiento es crucial para que la familia pueda asumir una actitud positiva en el proceso de atención educativa de sus representados. Por ello, conocer cada etapa psicológica, le permitirá identificarla para mediar en la búsqueda de mecanismos que faciliten la superación de la misma, hasta que el miembro del grupo familiar afectado alcance el nivel necesario para una implicación psicológica sana y comprometida en la atención educativa de sus hijos y/o representados. Para la consecución de esta conciencia, juega un papel crucial la mediación del docente de la MEE y otros profesionales, entre los cuales destacan psicólogos y trabajadores sociales.

\section{Active todos los recursos disponibles}

El docente de Educación Especial debe conocer cuáles son los recursos materiales y humanos necesarios para el desarrollo integral del educando con NEE que esté en la educación común; así como los recursos organizacionales, medios de comunicación de masas, entre otros. Estos representan una gran oportunidad a ser aprovechada por la comunidad escolar y amerita ser activada por este profesional en apoyo del docente de aula común y otros actores. La participación de todos los colectivos sociales que hacen vida activa en el hecho educativo es fundamental para la Educación Inclusiva.

\section{Informe a la comunidad en general sobre la documentación legal que sustenta la inclusión educativa}

Promoción a través de diversos canales de comunicación de la normativa Internacional, Nacional y Local, especialmente en cuanto a Derechos de los Educandos con NEE a la Educación Inclusiva. A continuación se nombran:

\section{Políticas y acuerdos mundiales:}

Declaración universal de los derechos humanos ONU (1948) Los derechos humanos como concepción educativa. Abraham Magendzo.

Declaración de los Derechos de los Niños. Asamblea Naciones Unidas (1959)

Declaración de los derechos de los Impedidos ONU (1960)

Declaración Universal de los Derechos de los impedidos. Asamblea Naciones Unidas 
Formación Del Docente De Educación Especial Y La Educación Inclusiva Como Política

Del Estado Venezolano

Debbiee Carmona de Sada, María Rodríguez Polanco

(Pp.27-49)

(1975)

Programa de Acción Mundial para los Impedidos. Asamblea Naciones Unidas (1981).

Convención Nacional sobre los Derechos del Niño (1989)

Cumbre Mundial de la Infancia (1990)

Ley aprobatoria sobre la convención de los Derechos del Niño (1990)

Normas Uniformes sobre la Igualdad de Oportunidades para la persona con

Discapacidad (1993)

Declaración de Salamanca sobre Integración de Personas con Discapacidad (1994)

Declaración Mundial sobre la Educación Superior en el Siglo XXI: Visión y Acción (1998)

Convención Iberoamericana para la Eliminación de todas las Formas de Discriminación contra las Personas con Discapacidad (1999)

XX Asamblea Ordinaria Parlamento Latinoamericano, carta Social de los Derechos de las Personas con Discapacidad.

\section{Normativa nacional y local:}

Constitución de la República Bolivariana de Venezuela (1999)

Conceptualización y Política de la Educación Especial en Venezuela (1976, 1989, 1997)

Ley Orgánica de Educación (2009).

Ley para la Integración de la Personas Incapacitadas (1993)

Ley Orgánica para la Protección del Niño y del Adolescente (LOPNA 1998)

Resolución No 2005 (1996)

Resolución No 1762 (1996)

Ley de Protección e Integración a Personas con Discapacidad en el estado Lara (Enero 2002)

Derecho de las Personas con Discapacidad a una Educación Superior de Calidad.

Dirección General de Asistencia Integral al Estudiante Ministerio de Educación Superior. Viceminesterio de Asuntos Estudiantiles. (2004).

Ley de las Personas con Discapacidad (2007). 
Resolución 2417 del MPPES. Lineamientos sobre el Ejercicio Pleno del Derecho de las Personas con Discapacidad a una Educación Superior con Calidad. Gaceta Oficial 38.731 (2007)

Conceptualización y Política de la Modalidad de Educación Especial (2016).

Fomenta la convivencia y propicia la participación comprometida entre todos los miembros de la comunidad educativa en la búsqueda de soluciones a las múltiples necesidades que presentan las personas con discapacidad como una forma de diversidad humana.

Esto supone la promoción y desarrollo de acciones o actividades de diferente índole, en las que haya la posibilidad de interacciones sociales: encuentros culturales, deportivos, recreativos, de carácter social, artísticos, académicos, de salud, entre otros.

1. Participe en la co-elaboración de proyectos institucionales, académicos y comunitarios

2. Además de ser co-autor de diversos proyectos, los monitorea y participa en su desarrollo y evaluación; involucrando a los diversos actores del hecho educativo.

3. Genere espacios de reflexión para la toma de conciencia ante realidades discapacitantes

4. Propicia actividades de encuentros dialógicos que activen un despliegue de cambios actitudinales en todos aquellos que requieren concretar actuaciones inclusivas.

5. Oriente y promueva la eliminación de expresiones discriminatorias, actuaciones segregadoras y barreras arquitectónicas

6. Elabora proyectos con organismos gubernamentales o no gubernamentales con miras a consolidar infraestructuras educativas y comunitarias accesibles: rampas; adecuación de servicios sanitarios y públicos como: bibliotecas, baños, teléfonos; señalización de vías de tránsito peatonal para personas con discapacidad visual, oportunidad para la presencia de intérpretes de lengua de señas venezolanas en los ambientes educativos, entre otros.

En el gráfico que sigue se presenta una consideración a la formación del docente de Educación Especial en el marco de la Educación Inclusiva. Se muestra la necesidad de un currículo con un fundamento axiológico inclusivo en dicha formación, tanto para el docente de Educación Especial como para el resto de las especialidades pedagógicas.

Considerar que el docente de la MEE tiene dos campos laborales por excelencia (en las unidades operativas de la MEE y en las instituciones educativas comunes en las que haya

Volumen $21 N^{\circ} 1$ Enero-Abril 2017. ISSN: 2244-7296 P 44 
Formación Del Docente De Educación Especial Y La Educación Inclusiva Como Política Del Estado Venezolano

Debbiee Carmona de Sada, María Rodríguez Polanco

(Pp.27-49)

educandos con NEE) es fundamental para comenzar a reflexionar en el tipo de formación que requiere. Por ello, es imperante que se acometan cambios en las conciencias de los formadores de docentes, de manera que se traduzcan en acciones pedagógicas inclusivas que trasciendan al resto de los niveles del Sistema Educativo Venezolano.

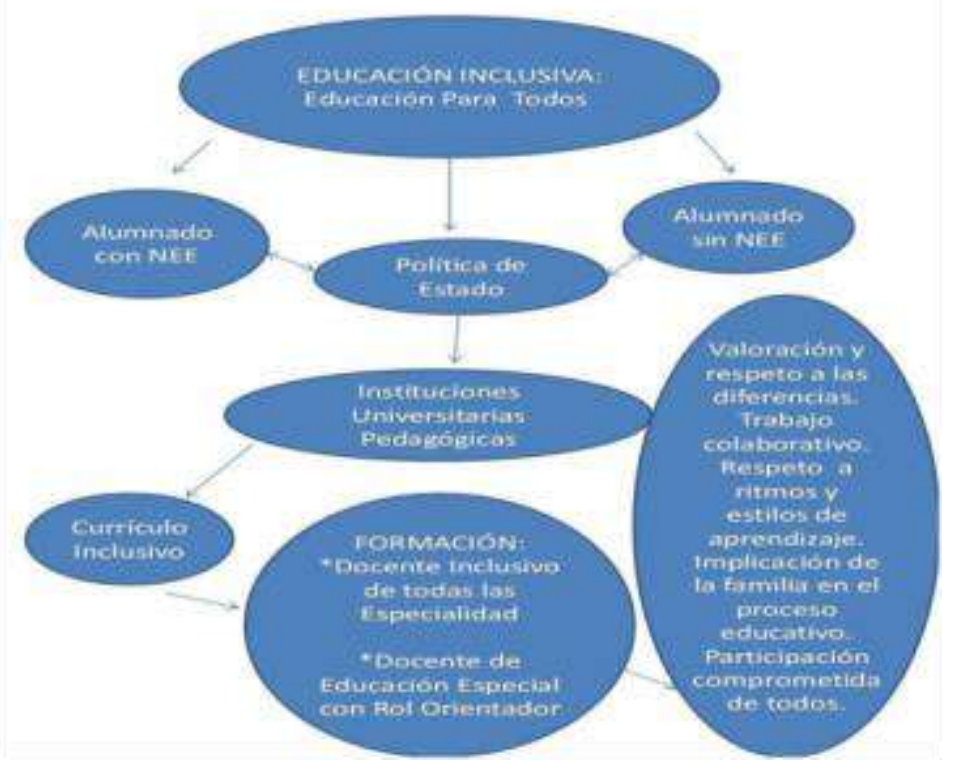

Gráfico1.Formación del Docente de Educación Especial en Marco de la Educación Inclusiva como Política de Estado.

Fuente: Autoras (2015)

\section{REFLEXIONES FINALES}

\section{Mirada al Horizonte}

En la actualidad, existe la necesidad de cristalizar los cambios que den apertura a la Educación Inclusiva, Política del Estado venezolano orientada a garantizar una educación para todos en los diferentes niveles del sistema educativo y modalidades; particularmente hacia las personas con discapacidad. Dicha Política está siendo revisada y reestructurada para su implementación efectiva.

Los maestros venezolanos ya están viviendo la experiencia de educar a niños, adolescentes, jóvenes y adultos con alguna discapacidad o NEE. Esto ha traído como 
consecuencia que el docente de la MEE necesite ampliar la visión de su marco de acción; ya que ahora su rol se extiende al trabajo mancomunado con todos los docentes, las familias y comunidad en general, y no solo en contextos educativos especiales.

Esta renovada mirada educativa debe permitir que el docente de Educación Especial co-construya con el resto de los actores sociales de la escuela y la comunidad, espacios inclusivos que promuevan la aceptación del otro, su reconocimiento, respeto a sus diferencias, la convivencia, el amor, la tolerancia y la justicia social.

Es imperativo hacer realidad las declaraciones y compromisos internacionales adoptados por nuestro país para hacer efectivo el derecho de todos los niños, niñas, adolescentes, jóvenes y adultos a la educación, la participación e igualdad de oportunidades.

Creemos que los cambios demandan la formación de docentes hacia una pedagogía flexible y heterogénea, reflexiva y crítica; capaz de hacer frente a una educación para la diversidad humana.

Asimismo, juzgamos que los docentes deben ir al encuentro con las familias, para abrirles posibilidades de participación comprometida en el proceso de enseñanza y aprendizaje de sus representados con NEE.

La idea es que el docente en general pueda impactar a la comunidad en la valoración de las diferencias como fuente de riqueza para la construcción de una sociedad más comprensiva. En este cometido, el docente de Educación Especial juego un papel catalizador fundamental en la consecución de esta demanda social, a través de asunción de las tareas que en este estudio se han presentado.

A partir de estas aseveraciones, se propone revisar la formación del docente de Educación Especial y considerar las transformaciones que en materia de políticas educativas se están generando e implementando en Venezuela; de tal forma, que se incorpore en el perfil del nuevo docente competencias que lleven a la conquista de una práctica con pertinencia social y política (no partidista).

Este docente debe tener competencias para reflexionar sobre su nuevo papel, y hacer frente a los retos que le reclama la sociedad venezolana, canalizados a través de las políticas públicas. Por lo tanto, consideramos que al docente de Educación Especial le 
corresponde co- liderar junto al resto de los actores del hecho educativo, el proceso de Educación Inclusiva que apenas se inicia en Venezuela.

Pero, son los docentes de las instituciones universitarias formadoras del nuevo educador, quienes deben iniciar la tarea transformadora desde los ámbitos de su desempeño laboral: La Docencia, Extensión e Investigación. Así mismo, deben asumir en el nuevo diseño curricular (para el caso de la UPEL-IPB) las actitudes y estrategias formativas idóneas para lograr el tránsito hacia la Educación Inclusiva. En definitiva, los pensum universitarios en la formación del docente de la MEE deben ser revisados.

Por lo pronto, hay barreras actitudinales que derribar y mucho camino que transitar. Es difícil concretar el cambio de una práctica educativa segregadora que está enquistada, a una praxis inclusiva, porque implica la compleja participación de gran número de personas (maestros, estudiantado, familias, personal de servicio, administrativos y otros) que necesitan orientaciones que fomenten la reflexión y la acometida de cambios concienciales y de acción en torno al proceso inclusivo.

La praxis parte del SER como germen del cambio; es por ello, que para el éxito de la Educación Inclusiva es fundamental el liderazgo de un docente de Educación Especial con su rol orientador renovador, amoroso, creativo, crítico empático y flexible.

En definitiva, la convivencia respetuosa y colaborativa de la comunidad en general, incluyendo a la propia persona con discapacidad, puede hacer posible la inclusión. Por lo tanto, consideramos que el rol que debe ejercer el docente de la MEE, representa la chispa que puede activar y desencadenar las interacciones humanas necesarias para hacer una realidad esa convivencia tolerante, y lograr que la inclusión pase de política muerta a realidad vivida. De allí, que la formación del docente de Educación Especial amerite de parte de las instituciones universitarias la revisión de su modelo de formación, para asumir impostergablemente los cambios que sean requeridos. 


\section{REFERENCIAS}

Belestrini, M. (2002). Procedimientos técnicos de la investigación documental. Orientaciones para la aplicación de las técnicas documentales y organización del trabajo escrito. Caracas, Venezuela: Consultores asociados BL. Servicio Editorial.

Durán y Climent (s/f). La formación del profesorado para la educación inclusiva: un proceso de desarrollo profesional y de mejora de los centros para atender la diversidad. Chile: Escuela de Educación Diferencial, Facultad de Ciencias de la Educación de la Universidad Central de Chile en colaboración con RINACE, Red Iberoamericana de Investigación sobre Cambio y Eficacia Escolar.

Finol, T. y Nava, H. (1996). Procesos y productos en la investigación documental. (2a . ed.). La Universidad del Zulia. Facultad Experimental de Ciencias. Rectorado.

Ministerio del Poder Popular para la Educación (2011). La transformación de la modalidad de educación especial, en el marco de la educación bolivariana" por una educación sin barreras. Caracas. Venezuela.

Morales, O. (1995).Fundamentos de la investigación documental y la monografíaDisponible: http://www.academia.edu/3468357/Fundamentos de la investigación abril 2014. [Consulta: 2013, Marzo 25]

Rodríguez, A. (2007). Actitud del docente egresado del programa de educación integral de la upel-ipb hacia la inclusión en la escuela común de niños, niñas y adolescentes con discapacidad. Trabajo de ascenso no publicado. UPEL-IPB.

Slee, R. (2012). La escuela extraordinaria, exclusión, escolarización y educación inclusiva.

Madrid: Editorial Morata.

Ugas, F. (2010). La complejidad de lo efímero. Barquisimeto, Venezuela: Ediciones Gema.

Universidad Pedagógica Experimental Libertador (2006). Manual de trabajos de grado de especialización y maestría y tesis doctorales. Caracas: FEDUPEL. 


\section{Formación Del Docente De Educación Especial Y La Educación Inclusiva Como Política}

Del Estado Venezolano

Debbiee Carmona de Sada, María Rodríguez Polanco

(Pp.27-49)

Universidad Pedagógica Experimental Libertador (2011). Documento base para la transformación del currículo. Caracas, Venezuela.

UNESCO (2007). Declaración universal sobre la diversidad cultural. Cumbre Mundial sobreel Desarrollo Sostenible. Johannesburgo.

UNESCO (2007). Educación para todos en el 2015 ¿alcanzaremos la meta? 